\title{
Life before birth: are the dice tossed for the rest of our lives?
}

\author{
Nanda N. J. Rommelse
}

Published online: 2 March 2012

(c) The Author(s) 2012. This article is published with open access at Springerlink.com

Without any exception, every human being has spent at least a considerable amount of time in the womb and has gone through the stressful process of being born. However, the quantity and quality of our life before birth varies tremendously between people. That is, some individuals survive birth after only 22 weeks of pregnancy [1] and others have the luxury of being born after spending more than 40 weeks in utero. Perhaps more importantly than the duration are the conditions of our stay: Do we receive enough and healthy nutrition? Are we exposed to toxics like tobacco, alcohol or drugs? Is the oxygen supply sufficient? Are we being subjected to high levels of stress hormones? Are we getting infected by bacteria or viruses? And then...birth. By some considered as the most stressful life event we will ever have to endure. A certain amount of stress is actually necessary for survival: The high level of hormones released during birth, which are also involved in the stress response, are believed to make the newborn more alert promoting the bonding process and, by extension, the child's physical survival [2]. However, while a certain amount of stress is necessary for survival, extreme and/or prolonged stress can affect health adversely [3]. For example, it has been shown that people who had underwent

N. N. J. Rommelse ( $\square)$

Karakter, Child and Adolescent Psychiatry University Center,

Nijmegen, The Netherlands

e-mail: N.Lambregts-Rommelse@ psy.umcn.nl

N. N. J. Rommelse

Department of Psychiatry, Radboud University Nijmegen

Medical Centre, Nijmegen, The Netherlands

N. N. J. Rommelse

Donders Institute for Brain, Cognition and Behaviour, Centre for Cognitive Neuroimaging, Radboud University Nijmegen, Nijmegen, The Netherlands an extremely stressful birth (defined as vaginal delivery with fetal suffering or forceps use, urgent cesarean section indicated by fetal suffering or twin birth with death of the other fetus) were 5 times more likely to have developed obsessive-compulsive disorder (OCD) in the year following a stressful life event compared to OCD patients without an extremely stressful birth [4]. In other words, the former group had more often a stress-event-related onset of OCD compared to the latter group, indexing the possibility that a very stressful birth creates a life-long enhanced vulnerability to stress and an enhanced risk of developing anxiety related symptoms, such as OCD. Animal studies also suggest that a single aversive life event may be capable of permanently affecting the individual's sensitivity towards experiences in life after birth [5].

The importance of a prosperous prenatal environment and birth process for future health has long been recognized. Conversely, exposure to early adversity during a sensitive period of development is thought to lead to structural, physiological and metabolic changes in the fetus that increase susceptibility to later disease [6]. For instance, antenatal maternal and infant malnutrition [7, 8], antenatal maternal stress [9], low birth weight, younger maternal age and increasing birth order [10-13] have all, amongst others, been linked to poorer mental health. Particularly in autism spectrum disorder (ASD), the role of adverse prenatal and perinatal factors is well-documented. Compelling evidence exists for associations between an increased risk for ASD on the one hand and maternal infections during pregnancy, increased parental age, fetal hypoxia, prematurity, and low birth weight on the other hand [14-16]. More broadly viewed, as reported by Guedeney et al. in this issue and previously by others [17-19], associations have been found between pre- and perinatal risks and sustained social withdrawal behavior (more prevalent than 
ASD but considered a red flag for developing clinical disorders such as ASD, attachment disorders and depression) [20-22]. In any case, life before birth is related to mental health outcomes in life after birth.

However, it remains to be determined to what extent these factors are true risk mediators (causally involved) or rather risk indicators (linked to an increased risk but not contributing causally to the adverse outcome). Two main reasons why prenatal risks may act as risk indicators, are that these factors are associated with postnatal risks (such as social adversity and parent mental health problems) and that they relate to unmeasured confounders, such as maternally transmitted inherited factors [6]. Studies commonly deal with these two possibilities by adjusting for measured confounders. For instance, it was recently shown that when social class, family structure and religion were corrected for, prenatal circumstances were not or only marginally associated with mental health outcomes in adolescence and young adulthood [23]. Further support for the hypothesis that perinatal factors may often act as indicators instead of mediators of poor mental health was reported in a series of elegantly designed studies by Thapar and colleagues [24-26]. Using genetically informative designs, in which mothers were either genetically related or unrelated to their child as a result of assisted reproductive technologies, they showed that relationships between smoking during pregnancy and ADHD and conduct disorder symptoms, and also between breastfeeding and lower levels of conduct problems, were only present in the genetically related group and not in the genetically unrelated group [24-26]. These studies teased apart the intrauterine and genetic influences normally intertwined in explaining the fetal origins of chronic diseases and suggest pre- and perinatal risk factors may sometimes act as a proxy for the underlying genetic risk transmitted to offspring.

However, elegant as these studies may be in examining the role of prenatal risks in isolation from a genetic background, the reality of life is that the vast majority of people are conceived in the natural way and spend their life before and after birth with their biological parents. Therefore, genetic and environmental factors correlate and interact in various complex ways, causing substantial differences between people in their exposure and susceptibility to both positive and negative environmental influences [27, 28]. This differential susceptibility may be labeled as "prenatal programming of postnatal plasticity" [29] and one of the mechanisms underlying this may be epigenetics. Epigenetics can be broadly defined as those heritable changes not dependant on the genomic sequence and encompasses a variety of mechanisms to dynamically modify the expression of the genome [30]. There appear to be "discrete epigenetic checkpoints" [30] during which the genome is extra sensitive to modifications by environmental factors. This illustrates that in real life there is no effect of prenatal risk in isolation from a genetic background or vice versa.

So, in life before birth, are the dice tossed for the rest of our lives? The influence of the prenatal environment on mental health later in life is unequivocally present. Often the dice are unfairly being tossed, with some children receiving the best of odds and others the worst. However, what the best odds are is not predetermined, but may vary according to the environment in which the child grows up. In some cases, the last shall be the first.

Open Access This article is distributed under the terms of the Creative Commons Attribution License which permits any use, distribution, and reproduction in any medium, provided the original author(s) and the source are credited.

\section{References}

1. Horemuzova E, Söder O, Hagenäs L (2012) Growth charts for monitoring postnatal growth at NICU of extreme preterm-born infants. Acta Paediatr 101(3):292-299

2. Cordon IM (1997). http://www.csun.edu/ vcpsy00h/students/ stress.htm

3. Bernard LC, Krupat E (1994) Health psychology: biopsychosocial factors in health and illness. Harcourt Brace College Publishers, New York

4. Real E, Labad J, Alonso P, Segalàs C, Jiménez-Murcia S, Bueno B, Subirà M, Vallejo J, Menchón JM (2011) Stressful life events at onset of obsessive-compulsive disorder are associated with a distinct clinical pattern. Depress Anxiety 28(5):367-376

5. Hougaard KS, Andersen MB, Kjaer SL, Hansen AM, Werge T, Lund SP (2005) Prenatal stress may increase vulnerability to life events: comparison with the effects of prenatal dexamethasone. Brain Res Dev Brain Res 159(1):55-63

6. Thapar A, Rutter M (2009) Do prenatal risk factors cause psychiatric disorder? Be wary of causal claims. Br J Psychiatry 195(2):100-101

7. Brown AS, van Os J, Driessens C, Hoek HW, Susser ES (2000) Further evidence of relation between prenatal famine and major affective disorder. Am J Psychiatry 157(2):190-195

8. Thompson C, Syddall H, Rodin I, Osmond C, Barker DJ (2001) Birth weight and the risk of depressive disorder in late life. Br J Psychiatry 179:450-455

9. O'Keane V, Scott J (2005) From 'obstetric complications' to a maternal-foetal origin hypothesis of mood disorder. Br J Psychiatry 186:367-368

10. Gravseth HM, Mehlum L, Bjerkedal T, Kristensen P (2010) Suicide in young Norwegians in a life course perspective: population-based cohort study. J Epidemiol Community Health 64(5):407-412

11. Riordan DV, Selvaraj S, Stark C, Gilbert JS (2006) Perinatal circumstances and risk of offspring suicide. Birth cohort study. $\mathrm{Br}$ J Psychiatry 189:502-507

12. Mittendorfer-Rutz E, Rasmussen F, Wasserman D (2004) Restricted fetal growth and adverse maternal psychosocial and socioeconomic conditions as risk factors for suicidal behaviour of offspring: a cohort study. Lancet 364(9440):1135-1140

13. Barker DJ, Osmond C, Rodin I, Fall CH, Winter PD (1995) Low weight gain in infancy and suicide in adult life. BMJ 311(7014): 1203 
14. Gardener H, Spiegelman D, Buka SL (2009) Prenatal risk factors for autism: comprehensive meta-analysis. $\mathrm{Br} \mathrm{J}$ Psychiatry 195(1):7-14

15. Gardener H, Spiegelman D, Buka SL (2011) Perinatal and neonatal risk factors for autism: a comprehensive meta-analysis. Pediatrics 128(2):344-355

16. Kolevzon A, Gross R, Reichenberg A (2007) Prenatal and perinatal risk factors for autism: a review and integration of findings. Arch Pediatr Adolesc Med 161(4):326-333

17. Lee PR, Brady DL, Shapiro RA, Dorsa DM, Koenig JI (2007) Prenatal stress generates deficits in rat social behavior: reversal by oxytocin. Brain Res 1156:152-167

18. Savonlahti E, Pajulo M, Ahlqvist S, Helenius H, Korvenranta H, Tamminen T, Piha J (2005) Interactive skills of infants with their high-risk mothers. Nord J Psychiatry 59(2):139-147

19. Hoy EA, Sykes DH, Bill JM, Halliday HL, McClure BG, Reid MM (1992) The social competence of very-low-birthweight children: teacher, peer, and self-perceptions. J Abnorm Child Psychol 20(2):123-150

20. Calkins SD, Fox NA (1992) The relations among infant temperament, security of attachment, and behavioral inhibition at twenty-four months. Child Dev 63(6):1456-1472

21. Egger HL, Angold A (2006) Common emotional and behavioral disorders in pre-school children: presentation, nosology, and epidemiology. J Child Psychol Psychiatry 47:313-337

22. Nadeau L, Tessier R, Descôteaux A (2009) Observed behaviours of pre-term children in a social play situation with classroom peers. Dev Neurorehabil. 12(4):201-206
23. Young R, Riordan V, Stark C (2011) Perinatal and psychosocial circumstances associated with risk of attempted suicide, nonsuicidal self-injury and psychiatric service use. A longitudinal study of young people. BMC Public Health 11:875

24. Shelton KH, Collishaw S, Rice FJ, Harold GT, Thapar A (2011) Using a genetically informative design to examine the relationship between breastfeeding and childhood conduct problems. Eur Child Adolesc Psychiatry 20(11-12):571-579

25. Thapar A, Rice F, Hay D, Boivin J, Langley K, van den Bree M, Rutter M, Harold G (2009) Prenatal smoking might not cause attention-deficit/hyperactivity disorder: evidence from a novel design. Biol Psychiatry 66(8):722-727

26. Rice F, Harold GT, Boivin J, Hay DF, van den Bree M, Thapar A (2009) Disentangling prenatal and inherited influences in humans with an experimental design. Proc Natl Acad Sci U S A 106(7):2464-2467

27. Belsky J (1997) Variation in susceptibility to rearing influences: an evolutionary argument. Psychol Inquiry 8:182-186

28. Belsky J (2005) Differential susceptibility to rearing influences: an evolutionary hypothesis and some evidence. In: Ellis B, Bjorklund D (eds) Origins of the social mind: evolutionary psychology and child development. Guilford Press, New York, pp 139-163

29. Pluess M, Belsky J (2011) Prenatal programming of postnatal plasticity? Dev Psychopathol 23:29-38

30. Zahir FR, Brown CJ (2011) Epigenetic impacts on neurodevelopment: pathophysiological mechanisms and genetic modes of action. Pediatr Res 69(5 Pt 2):92R-100R 